\title{
"Influencia da Época de Semeadura sôbre o Rendimento do Repôlho" (*)
}

\author{
Salim Simão
}

E. S. A. «Luiz de Queiroz»

(*) Recebido para publicação em 31/10/1960. 


\section{INTRODUÇÃO}

O Repolho, Brassica Oleraceae, L. variedade capiada é dentre as hortaliças uma das mais intensivamente cultivadas e se constitui em uma grande fonte econômica para o olericultor.

Segundo COUTO (1960) a temperatura exerce profunda influência no rendimento, sendo muitas vêzes a causa de insucessos. KNOTT (1951) diz que a época de semeadura é influenciada pela interação dos fatôres: temperatura e luz.

Com o intúito de se conhecer o comportamento dessa cruciferae durante o ano, iniciamos o presente trabalho:

\section{MATERIAL E MÉTODO}

Os ensaios foram levados a efeito na Escola Superior de Agricultura "Luiz de Queiroz", na Secção Técnica de Horticultura. A variedade utilizada foi Chato de Quintal, e os experimentos foram levados a efeito durante o ano de 1952 e 1953.

Fizeram-se sempre 4 repetições, contendo cada. parcela 100 plantas. As semeaduras foram feitas em alfobre e quando as mudas alcançavam $0,20 \mathrm{~m}$. de altura foram transplantadas para : local definitivo, distanciadas entre si de $0,60 \times 0,80$ metros. A adubação foi feita na cova, recebendo cada planta 1 quilo de matéria orgânica e mais a seguinte adubação mineral : Superfosfato de cálcio, $50 \mathrm{~g}$, Cloreto de potássio, $20 \mathrm{~g}$ e sulfato de amônio $30 \mathrm{~g}$. A colheita foi feita quando as plantas completavam 120 dias.

\section{RESULTADOS E DISCUSSÃO}

Apresentamos nos Quadros I e II os pêsos de 100 repolhos de cada uma das épocas de semeaduras, realizada em 1952 e 1953. 

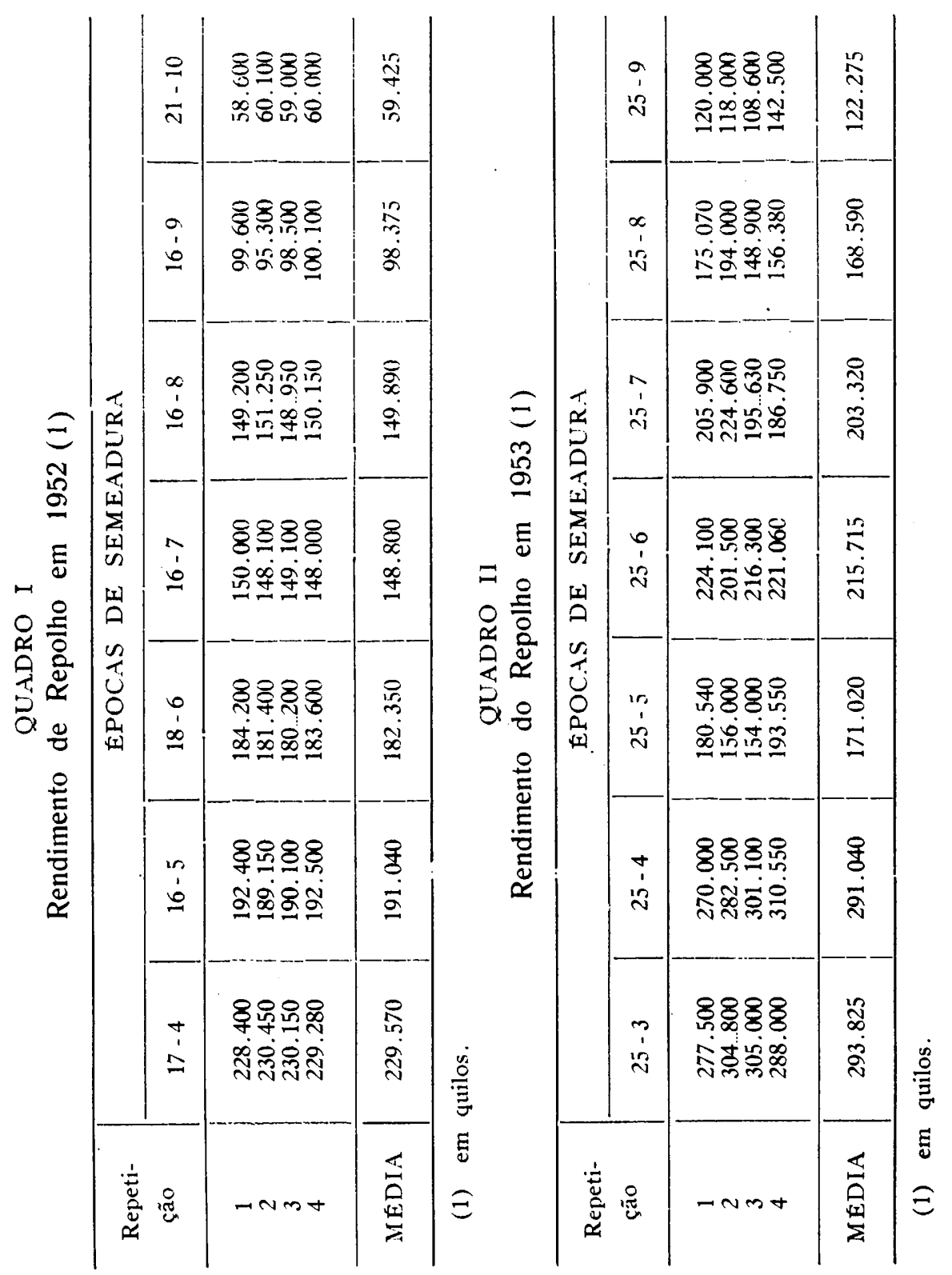

estatística.

Nos Quadros III e IV mostram os resultados das análises QUADRO III

Análise de variância dos dados de 1952

\begin{tabular}{l|r|r|c}
\hline \multicolumn{1}{c|}{ Causa da } \\
Variação & G.L. & \multicolumn{1}{|c|}{ S.Q. } & Q.M. \\
\hline Repetição & 6 & 1.081 .757 & \\
Meses & 4 & 797.740 .092 & $132.956 .682^{* * *}$ \\
Resíduo & 24 & 8.563 .762 & \\
\hline
\end{tabular}

As médias de tratamentos tôdas com êrro padrão de $3,445 \mathrm{~kg}$. são dadas abaixo :

\begin{tabular}{|c|c|}
\hline Abril & $229,570 \mathrm{~kg}$. \\
\hline Maio & $191,037 \mathrm{~kg}$ \\
\hline Junho $\ldots \ldots \ldots$ & $182,355 \mathrm{~kg}$ \\
\hline Julho & $157,800 \mathrm{k}$ \\
\hline Ágôsto & $149,887 \mathrm{~kg}$ \\
\hline Setembro $\ldots \ldots \ldots$ & $98,375 \mathrm{~kg}$. \\
\hline Outubro & $59,425 \mathrm{~kg}$ \\
\hline
\end{tabular}

A diferença minima ao nivel de $5 \%$ de probabilidade pelo teste de TUKEY, foi de $1,106 \mathrm{~kg}$. Por esta média verifica-se que as produções decresceram em escala contínua de abril para outubro, surgindo o mês de abril como o mais produtivo de todos, e o de outubro com a menor produção.

QUADRO IV

Análise de variância dos dados de 1953

\begin{tabular}{l|r|r|r}
\hline \multicolumn{1}{c|}{$\begin{array}{c}\text { Causa da } \\
\text { Variação }\end{array}$} & G.L. & \multicolumn{1}{|c|}{ S.Q. } & Q.M. \\
\hline Repetição & 3 & 399.472 .985 & \\
Meses & 6 & 98.001 .428 .190 & $16.333 .571 .348^{* *}$ \\
Resíduo & 18 & 5.593 .721 .125 & \\
\hline
\end{tabular}


As médias de tratamentos tôdas com êrro padrão de $8.814 \mathrm{~kg}$. são dadas abaixo :

$$
\begin{array}{lll}
25 / 3 & \ldots \ldots \ldots \ldots & 293,825 \mathrm{~kg} . \\
25 / 4 & \ldots \ldots \ldots \ldots & 291,037 \mathrm{~kg} . \\
25 / 6 & \ldots \ldots \ldots \ldots & 215,765 \mathrm{~kg} . \\
25 / 7 & \ldots \ldots \ldots \ldots \ldots & 203,320 \mathrm{~kg} . \\
25 / 5 & \ldots \ldots \ldots \ldots \ldots & 171,022 \mathrm{~kg} . \\
25 / 8 & \ldots \ldots \ldots \ldots \ldots & 168,587 \mathrm{~kg} . \\
25 / 9 & \ldots \ldots \ldots \ldots \ldots & 122,275 \mathrm{~kg} .
\end{array}
$$

A diferença minima significativa ao nivel de $5 \%$ de probabilidade calculada pelo teste de TUKEY, foi de $41,161 \mathrm{~kg}$. Por esta média podemos dizer que a primeira média difere de tôdas as outras médias, sendo a menos produtiva de tôdas a de setembro.

Se correlacionarmos as produções dos dois anos, 1952 e 1953, verificamos que em ambos o repolho obedeceu o mesmo rítmo de produção, isto é, sofreu sempre um decréscimo a partir da primeira para a última época de semeadura. Em 1953, ocorreu uma excessão, pois o mês de maio, quebrou a sequência, surgindo após o mês de Julho. Se computarmos os dados meteorológicos apresentados no gráfico II, com os da produção (Gráfico I), verificaremos que êste menor rendimento foi decorrente das mais baixas temperaturas reinantes durante o ciclo vegetativo das plantas semeadas em maio.

Verifica-se, ainda, que à medida que a temperatura se elevava, o rendimento caia bruscamente. Isto é fàcilmente compreendido, uma vez que as 'Brassicas, são plantas de inverno e sentem a elevação de temperatura segundo KNOTT (1961), e a cada dia que passa o comprimento do dia se eleva passando de 10 horas e 40 minutos em junho a 13 horas e 36 minutos em dezembro, provocando de um lado a maturação mais rápida da planta.

\section{CONCLUSÖES}

Pelos resultados obtidos as seguintes conclusões podem ser tiradas:

1 - O Repolho encontra condições melhores de vegetação durante as épocas mais temperadas do ano.

2 - A produção decresce de março para outubro devido as condições climáticas menos favoráveis ao desenvolvimento da planta. 


\section{SUMMARY}

The author carried out a study on the behavior of cabbage for a period of two years (1952 and 1953). From the results obtained it was concluded that, cabbage, Brassica oleraceae, var. capitata, developed better during the cooler season of the year, that is, from April to June and, the yield decresed from the beginning to the end of the sowing time, that is, from April to Ocotber.

\section{LITERATURA CITADA}

COUTO, F., 1960 - Culturas das Brassicas - ETA - Projeto 55 Viçosa.

KNOTT, J. E., 1951 - Palestras sôbre Horticultura. Ed. da Reiotria da Universidade de São Paulo. 231 págs... 

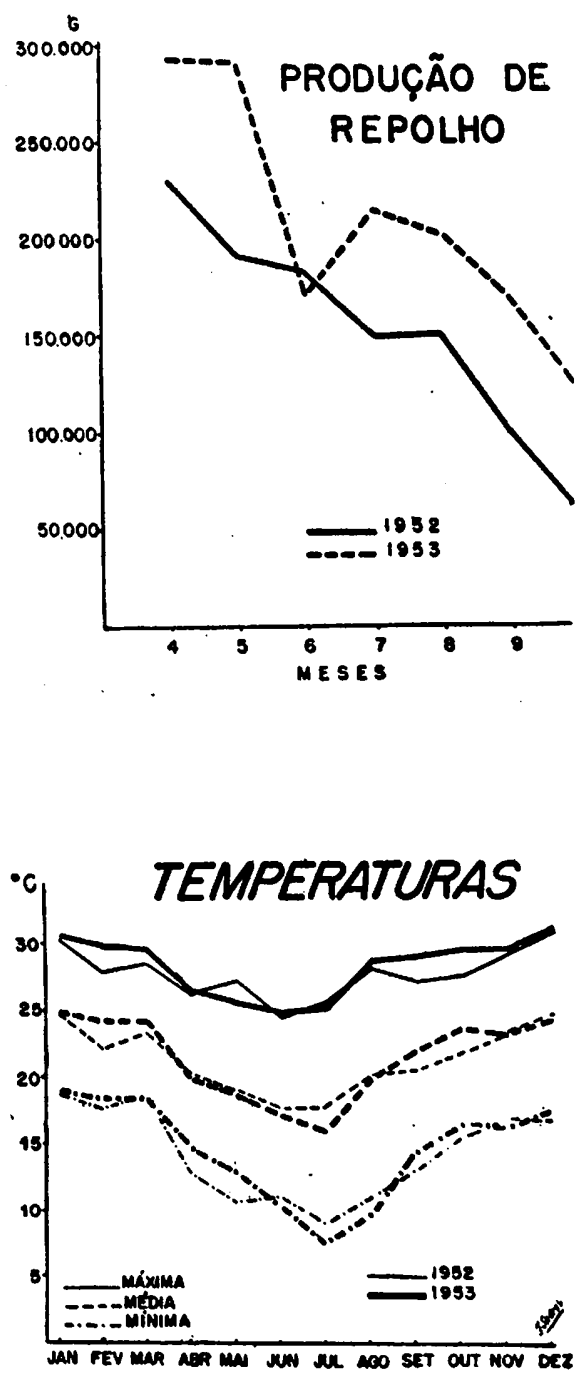
. 